\title{
Magnetic Resonance Monitoring of Disease Progression in $m d x$ Mice on Different Genetic Backgrounds
}

\author{
Ravneet Vohra, ${ }^{*}$ Abhinandan Batra, ${ }^{\dagger}$ Sean C. Forbes ${ }^{\dagger}$ Krista Vandenborne, $^{\dagger}$ and Glenn A. Walter ${ }^{*}$
}

From the Department of Physiology and Functional Genomics, ${ }^{*}$ College of Medicine, and the Department of Physical Therapy, ${ }^{\dagger}$ University of Florida, Gainesville, Florida

Accepted for publication

May 4, 2017.

Address correspondence to Glenn A. Walter, Ph.D., 1600 SW Archer Rd, M552, PO Box 100274, Gainesville, FL 326100274. E-mail: glennw@ufl.edu.

\begin{abstract}
Genetic modifiers alter disease progression in both preclinical models and subjects with Duchenne muscular dystrophy (DMD). Using multiparametric magnetic resonance (MR) techniques, we compared the skeletal and cardiac muscles of two different dystrophic mouse models of DMD, which are on different genetic backgrounds, the C57BL/10ScSn-Dmdmdx (B10-mdx) and D2.B10-Dmdmdx (D2-mdx). The proton transverse relaxation constant $\left(T_{2}\right)$ using both MR imaging and spectroscopy revealed significant age-related differences in dystrophic skeletal and cardiac muscles as compared with their age-matched controls. D2- $m d x$ muscles demonstrated an earlier and accelerated decrease in muscle $\mathrm{T}_{2}$ compared with age-matched B10-mdx muscles. Diffusion-weighted MR imaging indicated differences in the underlying muscle structure between the mouse strains. The fractional anisotropy, mean diffusion, and radial diffusion of water varied significantly between the two dystrophic strains. Muscle structural differences were confirmed by histological analyses of the gastrocnemius, revealing a decreased muscle fiber size and increased fibrosis in skeletal muscle fibers of D2-mdx mice compared with B10-mdx and control. Cardiac involvement was also detected in D2- $m d x$ myocardium based on both decreased function and myocardial $T_{2}$. These data indicate that MR parameters may be used as sensitive biomarkers to detect fibrotic tissue deposition and fiber atrophy in dystrophic strains. (Am J Pathol 2017, 187: 2060-2070; http://dx.doi.org/10.1016/j.ajpath.2017.05.010)
\end{abstract}

Duchenne muscular dystrophy (DMD) is a progressive and life-threatening X-linked muscular disorder caused by mutations in the dystrophin ( $d y s)$ gene. The $d y s$ gene encodes a 427-kDa cytoskeletal protein that forms the dystrophin/ glycoprotein complex at the sarcolemma with sarcoglycans, dystroglycans, and other proteins, and links the cytoskeleton of myofibers to the extracellular matrix in skeletal muscle. The lack of dystrophin perturbs the dystrophin/glycoprotein complex assembly and causes instability of the muscle membrane, leading to muscle degeneration and myofiber loss. The disease progression in DMD is characterized by degeneration, necrosis, accumulation of fat and fibrosis, and insufficient regeneration of myofibers accompanied by a loss of myofibers.

Animal models have helped advance the understanding of the underlying pathological changes that occur in the muscular dystrophies. The histopathological findings associated with mutation in the $d y s$ gene are similar in both human patients and the murine models of muscular dystrophy. ${ }^{1-4}$ Although the $m d x$ mouse model is one of the most commonly used animal models for DMD, it has a milder phenotype compared with patients with DMD., Despite the fact that $m d x$ mice display a milder skeletal muscle phenotype, they have been used to develop and demonstrate proof of principle for many therapeutic

\footnotetext{
Supported by NIH Paul D. Wellstone Muscular Dystrophy Cooperative Research grant U54AR052646 (G.A.W.) and Department of Defense grant MD110050 (G.A.W.). A portion of this work was performed in the McKnight Brain Institute at the National High Magnetic Field Laboratory's Advanced Magnetic Resonance Imaging and Spectroscopy Facility, which is supported by National Science Foundation Cooperative Agreement DMR-1157490 and the state of Florida.
}

Disclosures: None declared. 
approaches, including gene therapy, ${ }^{7,8}$ stop codon suppression drugs,,${ }^{9,10}$ RNA splicing,,${ }^{11,12}$ and stem cell therapies. ${ }^{13}$

Mounting evidence has uncovered the presence of genetic modifiers that lead to phenotypic variability even with an identical gene mutation. ${ }^{14-17}$ Moreover, both $m d x$ and a mouse model of limb girdle muscular dystrophy $\left(\mathrm{Sgcg}^{-/-}\right)$ bred on the $D B A / 2 J$ background display a more severe phenotype compared with other backgrounds, ${ }^{18,19}$ suggesting a role of genetic modifiers in disease progression. In addition, evidence in the literature supports that animal models on the DBA/2J strain are more severely affected than C57BL10 and C57BL6 backgrounds. ${ }^{20,21}$ In recent years, $m d x$ mice on the $D B A / 2 J$ background [ie, D2.B10$\left.D m d^{m d x}(\mathrm{D} 2-m d x)\right]$ mouse model has emerged as an alternative mouse model, which has been proposed to parallel human disease progression more closely than the contemporary $m d x$ mouse model on the BL10 background (ie, B10- $m d x){ }^{18,20}$ In addition, disease progression varies between individual muscles and is an important factor to consider in future and especially longitudinal studies. ${ }^{22,23}$ This limitation can be overcome by using sensitive noninvasive imaging biomarkers. ${ }^{24-27}$ Magnetic resonance imaging (MRI) has emerged as a robust and sensitive tool that can be used to monitor natural disease progression and efficacy of therapeutic interventions. ${ }^{28-34}$

The skeletal muscles and myocardium contain a variety of tissues characterized by differences in proton transverse relaxation time constants $\left(T_{2}\right)$. These alterations in $T_{2}$ have been attributed to muscle damage, ${ }^{35}$ edema,${ }^{36-38}$ fatty tissue infiltration, ${ }^{39}$ and fibrosis. ${ }^{40,41}$ Similar to skeletal muscle MRI, cardiac magnetic resonance has emerged as a sensitive diagnostic tool to detect cardiac dysfunction in DMD patients. ${ }^{42-44}$ Cardiac magnetic resonance is a noninvasive tool that allows three-dimensional volumetric measurement analysis to detect global cardiac functions and strain measures. Recent studies in infarcted/fibrotic cardiac tissue and in tissue phantoms have shown that both $\mathrm{T}_{2}$ and $\mathrm{T}_{2}^{*}$ are linearly related to collagen content and tissue fibrosis based on staining for collagen ${ }^{45}$ and hydroxyproline assay. ${ }^{46}$ Similar to the skeletal muscle, the $m d x$ mouse model initially presents with a mild cardiac phenotype, but at older ages they progress to a dilated cardiomyopathy. ${ }^{47}$

The primary purpose of this study was to monitor the changes in skeletal and cardiac muscles of D2- $m d x$ mice using MRI as a noninvasive biomarker, which is evolving as a new model for DMD that closely mimics the pathological changes occurring in DMD. Using MRI and magnetic resonance spectroscopy, we assessed longitudinal changes in muscle pathology and compared these longitudinal changes to age-matched control using DBA/2J and B10- $m d x$ mice. Also, at a single age time point, we determined cardiac function and water diffusion in their skeletal muscles. Histological verification was made based on trichrome and hematoxylin and eosin (H\&E) staining to quantify muscle fiber size changes and fibrotic tissue deposition in the skeletal muscles from each strain.

\section{Materials and Methods}

\section{Animal Handling and Care}

The study was conducted with the approval from the University of Florida (Gainesville) Institutional Animal Care and Use Committee. Five-week-old, specific pathogen-free mice DBA/2J; DBA2 ( $n=5$ males), C57BL/10ScSn, C57BL10 ( $n=5)$, C57BL/10ScSnDmd $m d x ; \quad \mathrm{B} 10-m d x \quad(n=5$ males $)$, and D2.B10$D m d^{m d x}$;D2-mdx $(n=5$ males $)$ were obtained from Jackson Laboratories (Bar Harbor, ME) and thereafter maintained in house until 7 months of age. Mice were fed ad libitum and were housed in an Association for Assessment and Accreditation of Laboratory Animal Care International-accredited animal facility in a temperature $\left(22^{\circ} \mathrm{C} \pm 1{ }^{\circ} \mathrm{C}\right)$, humidity $(50 \% \pm 10 \%)$, and light (12-hour light/dark cycle) controlled room.

\section{Magnetic Resonance Imaging}

\section{Hindlimb Muscle Imaging}

MRI was performed in a 4.7-T, horizontal bore magnet (VMJ version 3.1; Agilent, Santa Clara, CA). Throughout MRI, animals were anesthetized using an oxygen and isoflurane mixture (3\% isoflurane) and maintained under $0.5 \%$ to $1 \%$ isoflurane while their respiratory rate was monitored (Small Animal Instruments, Stony Brook, NY). The lower hindlimbs of the mouse were inserted up to the knee into a 2.0-cm internal diameter, custom-built solenoid ${ }^{1} \mathrm{H}$ coil (200 $\mathrm{MHz}$ ). Three-dimensional gradient images were acquired with the following parameters: field of view (FOV), $15 \times 15 \times 15 \mathrm{~mm}^{3}$; matrix size, $256 \times 192 \times 96$; repetition time (TR), 50 milliseconds; echo time (TE), 7 milliseconds; number of signal averages, 2; flip angle, 40 degrees. In addition, $\mathrm{T}_{2}$-weighted, multiple-slice, single spin-echo MR images were acquired with the following parameters: TR, 2000 milliseconds; TE, 14 and 40 milliseconds; FOV, 10 to $20 \mathrm{~mm}$; slice thickness, 0.5 to $1 \mathrm{~mm}$; acquisition matrix, $128 \times 256$; and number of signal averages, 2. Hahn spin echo was implemented to avoid the contribution of stimulated echoes in the $\mathrm{T}_{2}$ measurement. ${ }^{48}$ $\mathrm{T}_{2}$ was calculated assuming a single exponential decay. ${ }^{49}$ To eliminate the potential of lipid changes on $T_{2}$ and increase TE sampling, ${ }^{1} \mathrm{H}_{2} \mathrm{O}$ spectroscopic relaxometry was implemented using a single voxel within the posterior muscle compartment using stimulated echo acquisition mode under the following parameters: voxel size, $1.5 \times 3.0 \times 1.5 \mathrm{~mm}^{3}$; TR, 9000 milliseconds; 29 unequally spaced TEs from 5 to 200 milliseconds $(5,6,7,8$, $9,10,15,20,25,30,35,40,45,50,55,60,65,70,80,90$, $100,110,120,130,140,150,160,170$, and 200); mixing time, 20 milliseconds; and number of phased cycled averages, 4. Water amplitude as a function of TE was determined using complex principal component analysis, as previously described. ${ }^{50}$ The decay in water signal amplitude 
was fit to a single exponential decay. ${ }^{51}$ This allowed for the acquisition of highly TE-sampled T2 decay with high signal/noise ratio (approximately 4500), which was calculated as previously published. ${ }^{52,53}$ Finally, spin-echo diffusion tensor image data were acquired using the following parameters: b-value, 900 seconds $/ \mathrm{mm}^{2}$; TE/TR, 21/1000; and number of signal averages, 2. FOV, slice thickness/gap, and acquisition matrix were $20 \times 20 \mathrm{~mm}^{2}, 1 \mathrm{~mm} / 0 \mathrm{~mm}$, and $128 \times 128$, respectively, yielding a voxel resolution of $0.16 \times 0.16 \times 1.00 \mathrm{~mm}^{3}$. The signal/noise ratio of images with minimum $b$ value was 29.25 , and that with $b=900$ seconds $/ \mathrm{mm}^{2}$ is 13.11 .

\section{Cardiac Magnetic Resonance Imaging}

After anesthesia, mice were positioned supine on a homebuilt setup that allowed monitoring of body temperature, respiratory rate, and heart rate (Small Animal Instruments). The average body temperature of the mice was $34^{\circ} \mathrm{C}$, and their respiratory rate was 50 to 60 breaths/minute. ECG electrodes were inserted in limbs of mice, and a respiration pad was taped across the abdomen. Mice were maintained under anesthesia (1\% to $1.5 \%)$ via nose cone and were placed in a magnet. Body temperature was maintained using a regulated circulated water heater. The temperature of water was maintained between $45^{\circ} \mathrm{C}$ and $50^{\circ} \mathrm{C}$. Mice were imaged using a $3.3-\mathrm{cm}$ diameter quadrature birdcage volume coil. A series of five transverse images were acquired over the heart after power calibration and global shimming scans. Single-slice long axis axial and sagittal scans were acquired to view the apex and base of the heart. These long axis scans were used to obtain the short axis scans, which were then used to measure ventricular function. Left and right ventricles were imaged using a stack of short axis images with 1-mm slice thickness. Images were acquired using a spoiled gradient-echo cine sequence (TR, 110 milliseconds; TE, 1.37 milliseconds; flip angle, 15 degrees; FOV, $25 \times 25 \mathrm{~mm}^{2}$; data matrix, $128 \times 128$; and slice thickness, $1 \mathrm{~mm}$ ). Twelve cine frames were acquired through the cardiac cycle and were ECG triggered to $\mathrm{R}$ wave with R-R delay of 110 milliseconds and delay of 0.2 milliseconds. In addition, gated $\mathrm{T}_{2}$ weighted single spin echo images of the left ventricle in the short axis view were acquired using the following parameters: TR, 750 milliseconds; TE, 12 and 30 milliseconds; FOV, $25 \times 25 \mathrm{~mm}^{2}$; slice thickness, $1.0 \mathrm{~mm}$; acquisition matrix, $256 \times 128$; averages, 8 . Short axis slices from the midpapillary region were selected to calculate mean $\mathrm{T}_{2}$.

\section{Histology}

Hindlimb muscles were carefully extracted and stored for further analyses. Specifically, posterior compartment muscles (gastrocnemius and soleus) were extracted and embedded in TissueTek OCT compound (Sakura Finetek, Torrance, CA) and frozen using isopentane chilled in liquid nitrogen. Frozen sections ( $8 \mu \mathrm{m}$ thick) were obtained from the mid belly region of gastrocnemius (GAS) muscle using a cryostat (Leica Microsystems, Solms, Germany). Multiple sections were taken and kept at room temperature for 20 to 30 minutes before staining them with $\mathrm{H} \& \mathrm{E}$ working solution (Surgipath, Buffalo Grove, IL). In addition, Masson trichrome staining was used to detect fibrotic tissue accumulation and was performed per manufacturer's instructions.

\section{MR Analysis}

\section{Hindlimb Muscles}

Images were converted to Digital Imaging and Communication in Medicine format using a custom written IDL code for Varian data (Exelis, Colorado Springs, CO). Anterior and posterior compartments were outlined on axial images of the whole limb to determine maximum cross-sectional area $\left(\mathrm{CSA}_{\max }\right)$ of individual compartments, as described previously. ${ }^{41,54}$ Briefly, $\mathrm{CSA}_{\max }$ was calculated as the mean of the consecutive three slices having the greatest CSA for both anterior and posterior compartments separately. Furthermore, muscle MR- $T_{2}$ values of anterior and posterior compartments were computed and analyzed using $T_{2}$ maps, generated from two echo times (TEs, 14 and 40 milliseconds) using OsiriX software version 3.9.4 (Pixmeo, Geneva, Switzerland), an opensource Digital Imaging and Communication in Medicine viewer and analysis software. To improve the coverage and reliability, muscle MR- $\mathrm{T}_{2}$ values of the middle six to eight slices from the anterior and posterior compartments were computed. $T_{2}$ was calculated using the following equation:

$$
\mathrm{T}_{2}=\frac{(26 \text { milliseconds })}{\ln (\text { SI } 14 / \mathrm{SI} 40)},
$$

where SI 14 and SI 40 are the pixel intensities at a TE of 14 and 40 milliseconds, respectively. Muscle water-only $\left({ }^{1} \mathrm{H}_{2} \mathrm{O}-\mathrm{T}_{2}\right)$ data were analyzed using a custom written software in IDL (Exelis). Specifically, ${ }^{1} \mathrm{H}_{2} \mathrm{O}-\mathrm{T}_{2}$ was determined by a nonlinear curve fitting the decay in water signal as a function of TE using a monoexponential model and nonnegative least squares (Supplemental Figure S1). ${ }^{50,55}$ Finally, using a validated $^{56}$ IDL-based MRI analysis software version 00020170123 (http://marecilab.mbi.ufl.edu/software/MAS; last accessed March 30, 2017), mean diffusivity, radial diffusivity, fractional anisotropy (FA), and eigenvalues $(\lambda 1$, $\lambda 2, \lambda 3$ ) were all determined within a region of interest in posterior compartment muscles (GAS-soleus complex). Mean diffusivity and radial diffusivity were calculated using $(\lambda 1+\lambda 2+\lambda 3 / 3)$ and $(\lambda 2+\lambda 3 / 2)$, respectively. After the last MR examination of the mice at 7 months of age, hindlimb muscles were extracted for histological examinations.

\section{Myocardial Function}

Left ventricular function was analyzed using cine images. Seven to eight series of frames were acquired covering the 
whole heart (apex to base of the heart). The end diastolic volume and end systolic volume were measured for each slice and summed over the whole heart. Stroke volume was calculated as: end diastolic volume - end systolic volume.

Furthermore, ejection fraction was calculated as stroke volume/end diastolic volume.

In addition, left ventricular mass was calculated using myocardial area $\times$ slice thickness $\times$ myocardial density (1.05) ${ }^{57,58}$ Finally, mean myocardial $\mathrm{T}_{2}$ was calculated using the average signal intensity at each TE by manually tracing the myocardium, at the midsection of the heart, using OsiriX software.

\section{H\&E Staining and Trichrome Stains}

Slides were imaged using a digital camera (Leica Microsystems) and analyzed using ImageJ software version $1.48 \mathrm{v}$ (NIH, Bethesda, MD; http://imagej.nih.gov/ij). The average muscle fiber size was determined by using a similar approach as described previously. ${ }^{54}$ Cryostat sections ( 8 to $10 \mu \mathrm{m}$ thick) in a transverse plane were cut in the middle section of the muscle and stained with H\&E stains. Stained cross sections were imaged using a Leica fluorescence microscope with a digital camera. Muscle fiber cross section area was measured using NIH ImageJ software. All of the muscle fibers were circled, and fiber area was recorded for 150 to 200 muscle fibers.

In addition, fibrotic area was quantified by dividing fibrotic tissue (blue stain) by the total cross-sectional area of the entire tissue section.

\section{Statistical Analysis}

All statistical analyses were performed using GraphPad Prism software version 6 (GraphPad Software Inc., La Jolla, CA) and included one-way analysis of variance, followed by Tukey multiple comparisons test. In addition, a paired $t$-test was used to demonstrate age-dependent changes in anterior and posterior compartment muscles. All data are presented as means $\pm \mathrm{SD}$, unless otherwise specified. Statistical significance was set at $P<0.05$.

\section{Results}

\section{Reduced Body and Muscle Weight in D2-mdx Mice}

As an overall measure of animal health, we monitored the body weight of all animals on a weekly basis. Although there was an age-dependent increase in body weight in all of the groups, B10- $m d x$ weighed more than D2- $m d x$ and DBA2 mice at all ages (Figure 1$)(P<0.01)$. At the 7-month time point, hindlimb muscles (tibialis anterior, extensor digitorum longus, GAS, and soleus) of D2- $m d x$ mice were all extracted and weighed (Figure 2). The tibialis anterior and GAS of D2- $m d x$ mice weighed significantly less than the equivalent muscles from $\mathrm{B} 10-m d x$ mice $(P<0.001)$.

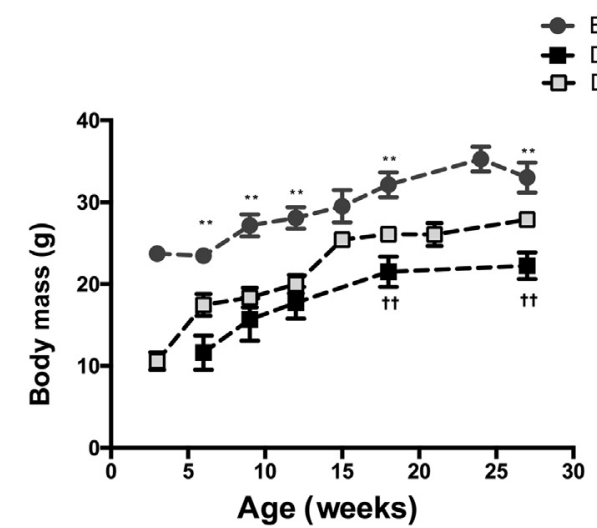

Figure 1 Body mass reduction in D2- $m d x$ mice compared with B10- $m d x$ mice at all time points. In addition, after 15 weeks of age, D2-mdx mice weigh significantly less than age-matched DBA2 mice. ${ }^{*} P<0.01$ between B10- $m d x$ and D2- $m d x ;{ }^{\dagger \dagger} P<0.01$ between DBA2 and D2- $m d x$ muscles.

\section{Reduced Muscle $\mathrm{CSA}_{\max }$}

MRI was implemented to quantify in vivo differences in muscle size in the different experimental groups. CSA $_{\max }$ values of anterior and posterior compartment muscles were compared among different groups at the 26-week time point (Supplemental Figure S2). In addition, the relationship between $\mathrm{CSA}_{\max }$ (posterior compartment) and muscle wet weight (sum of GAS and soleus) obtained at the 7-month time point was determined. A strong correlation $(r=0.97)$ was found between two measures (Figure 3) and further illustrates the small muscle masses in D2- $m d x$ mice.

\section{Age-Dependent Alterations in Muscle $\mathrm{T}_{2}$}

The magnetic resonance spectroscopy-determined water $\mathrm{T}_{2}$ $\left({ }^{1} \mathrm{H}_{2} \mathrm{O}-\mathrm{T}_{2}\right)$ values clearly revealed differences between the
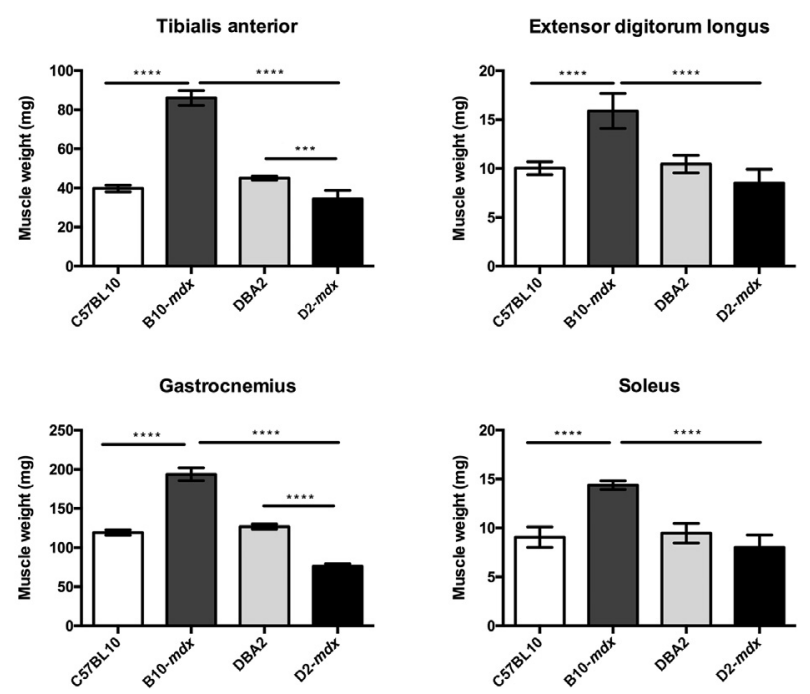

Figure 2 Muscle wet weight of different muscles at age of 7 months, showing significant differences among different groups. Data are expressed as means \pm SD. ${ }^{* *} P<0.001,{ }^{* * * *} P<0.0001$. 


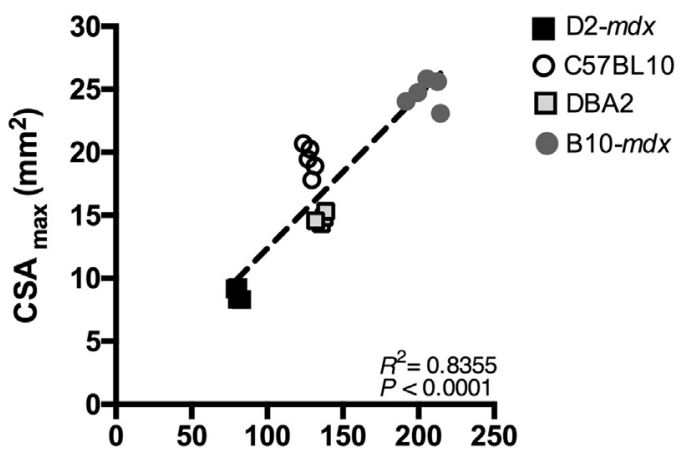

Triceps surae muscle wet weight (mg)

Figure 3 Correlation between wet weight and $\mathrm{CSA}_{\max }$ of triceps surae muscles of D2- $m d x$, C57BL10, DBA2, and BL10- $m d x$ mice at 7 months of age.

different mouse cohorts (Figure 4A). Of interest was the rapid decline in $m d x$-dba muscle $\mathrm{T}_{2}$ values significantly below that of DBA-2 at 26 weeks of age. Although B10$m d x$ muscles also decreased over this period, they did not decrease below the level of C57BL10 ${ }^{1} \mathrm{H}_{2} \mathrm{O}-\mathrm{T}_{2}$, even at the oldest ages that were measured in this study (Figure 4). At 6 months of age, ${ }^{1} \mathrm{H}_{2} \mathrm{O}-\mathrm{T}_{2}$ values were significantly $(P=0.001)$ reduced in both $\mathrm{B} 10-m d x(27.5 \pm 0.8$ milliseconds) and D2-mdx (22.8 \pm 0.9 milliseconds) mice compared with their baseline measurement at 6 weeks of age (B10- $m d x, 33.8 \pm 3.2$ milliseconds; D2- $m d x, 30.4 \pm 3.8$ milliseconds). At 6 months of age, B10- $m d x$ demonstrated significantly higher ${ }^{1} \mathrm{H}_{2} \mathrm{O}-\mathrm{T}_{2}$ than age-matched C57BL10 $(27.5 \pm 0.8$ versus $25.15 \pm 0.34$ milliseconds; data not shown). Interestingly, after 6 months of age, D2-mdx mice showed significantly reduced ${ }^{1} \mathrm{H}_{2} \mathrm{O}-\mathrm{T}_{2}$ values compared with control DBA2 mice (D2- $m d x$ versus DBA2, $22.8 \pm 0.9$ versus $25.6 \pm 0.7$ milliseconds; $P<0.005)$. Natural history changes in muscle $\mathrm{T}_{2}$ (MRI- $\mathrm{T}_{2}$ ) demonstrate an agedependent decline in $\mathrm{T}_{2}$ in D2-mdx mice. MRI- $\mathrm{T}_{2}$ values from anterior and posterior compartments of D2- $m d x$ mice were significantly reduced at the 26-week time point (means $\pm \mathrm{SD}$; anterior compartment, $22.3 \pm 0.5$ milliseconds; posterior compartment, $22.1 \pm 1.1$ milliseconds; $P<0.01$ ) compared with the 6-week time point (anterior compartment, $28.7 \pm 3.5$ milliseconds; posterior compartment, $28.7 \pm 1.2$ milliseconds; $P<0.01$ ) (Figure 4B), which are demonstrated as a decrease in hyperintense areas on $\mathrm{T}_{2}$-weighted axial images (Figure $4 \mathrm{C}$ ). On the contrary, we did not find any significant age-dependent decrease in MRI-T ${ }_{2}$ of C57BL10 muscles between the ages of 6 and 26 weeks (anterior compartment, $23.52 \pm 1.0$ versus $22.9 \pm 0.6$ milliseconds; posterior compartment, $24.8 \pm 0.8$ versus $23.4 \pm 0.8$ milliseconds).

\section{Strain-Dependent Differences in Muscle Diffusion}

At 7 months of age, we performed diffusion tensor measurements in C57BL10, B10-mdx, DBA2, and D2- $m d x$ mice (Figure 5). The mean diffusivity was significantly reduced in both dystrophic models compared with their strain-dependent controls [ie, B10-mdx $\left(1.4 \times 10^{-3} \pm\right.$ $\left.5.7 \times 10^{-5} \mathrm{~mm}^{2} / \mathrm{second}\right)$ versus C57BL10 $\left(1.6 \times 10^{-3} \pm\right.$ $2.7 \times 10^{-5} \mathrm{~mm}^{2} /$ second $)$ and D2-mdx muscles $\left(1.3 \times 10^{-3}\right.$
A

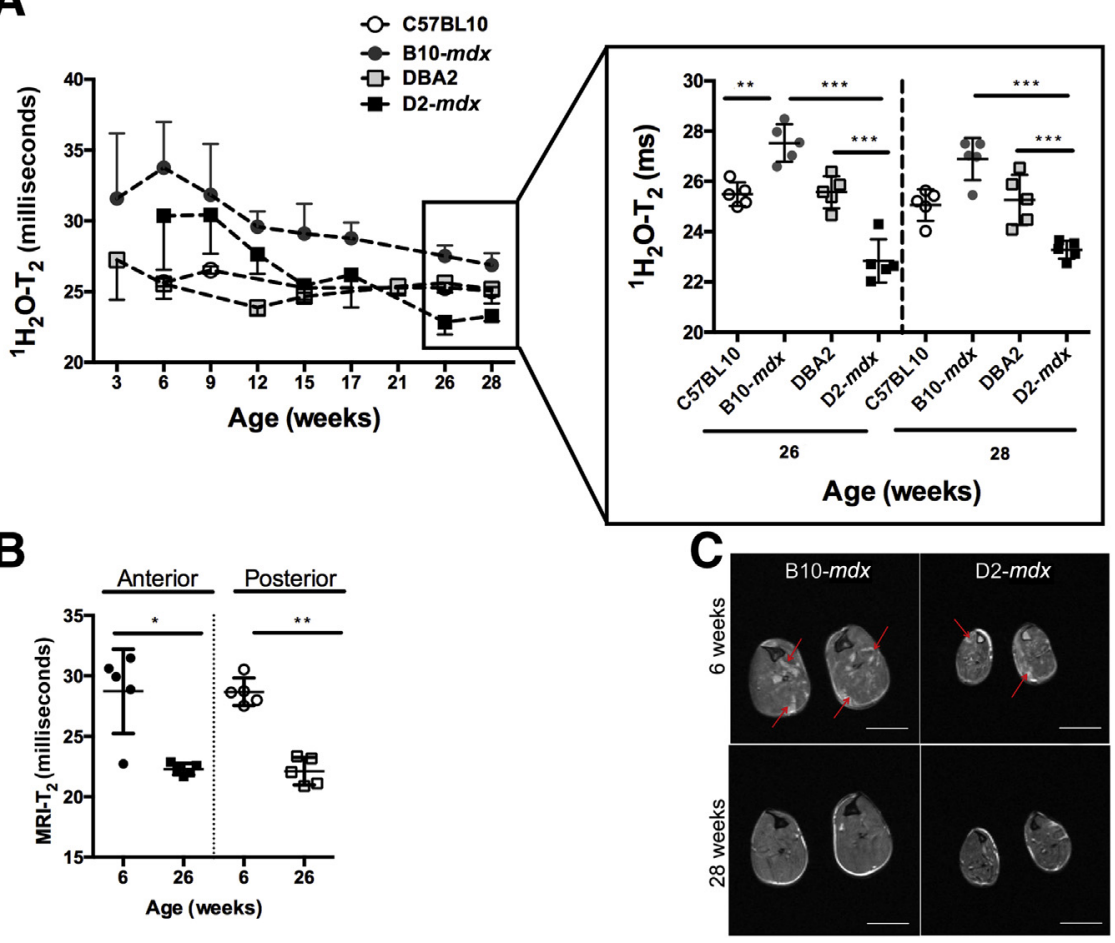

Figure 4 A: Time course of ${ }^{1} \mathrm{H}_{2} \mathrm{O}-\mathrm{T}_{2}$ changes in posterior hindlimb muscles of B10-mdx, DBA2, and D2- $m d x$ mice. In addition, significant differences are seen among groups at 26 and 28 weeks of age. B: Longitudinal MRI-T $T_{2}$ of anterior and posterior compartment muscles of D2-mdx mice, demonstrating a significant decrease at 26 weeks of age. C: Axial $T_{2}$-weighted MR images of B10-mdx and D2- $m d x$ mice, aged 6 and 28 weeks, showing presence of hyperintense areas in anterior and posterior compartment at 6 weeks of age (red arrows), but these hyperintense areas are absent at 28 weeks of age. In addition, both B10-mdx and D2- $m d x$ demonstrate significant differences in the size of the anterior and posterior hindlimb muscle compartments. ${ }^{*} P<0.05,{ }^{*} P<<0.01$, and $* * * P<0.001$. Scale bar $=2 \mathrm{~mm}$ (C). 

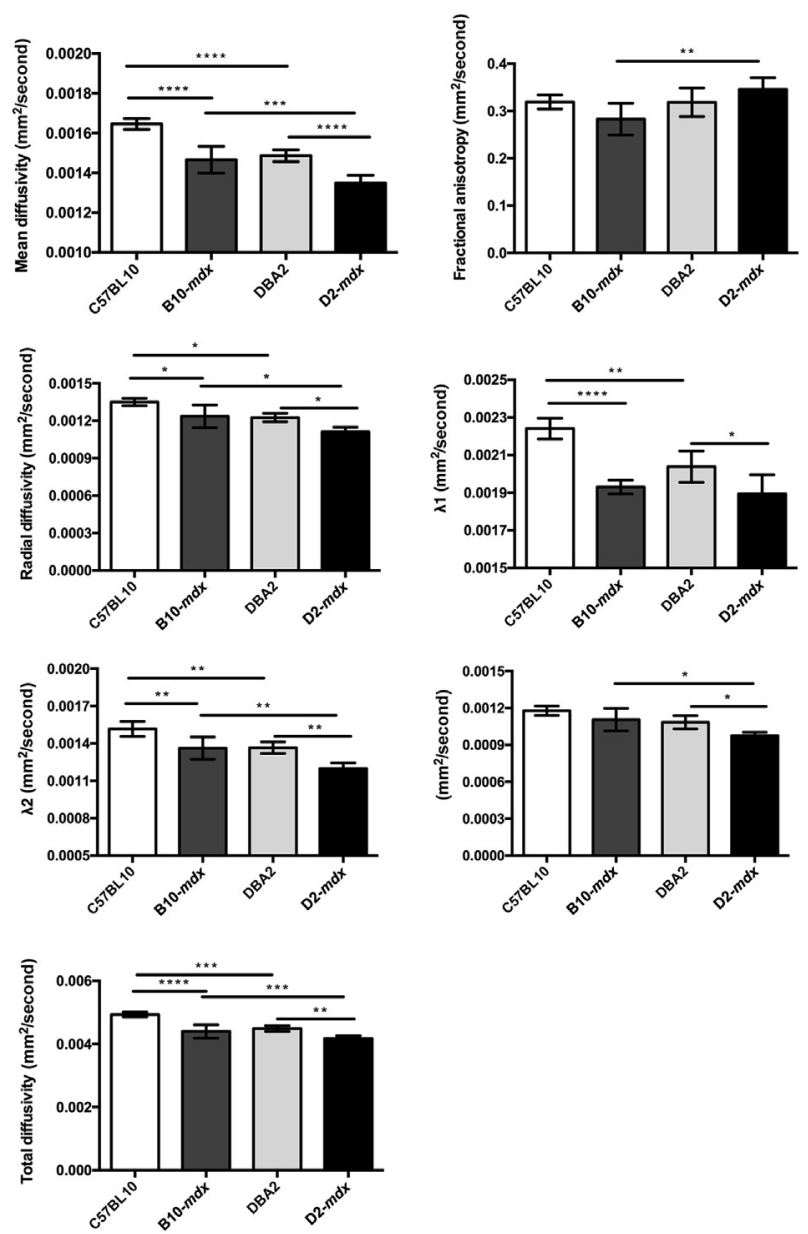

Figure 5 Diffusion tensor image parameters demonstrating significant differences among different groups. Data are expressed as means \pm SD. ${ }^{*} P<0.05,{ }^{* *} P<0.01,{ }^{* * *} P<0.001$, and ${ }^{* * * *} P<0.0001$.

$\pm 4.0 \times 10^{-5} \mathrm{~mm}^{2} /$ second $)$ versus DBA2 $\left(1.5 \times 10^{-3} \pm\right.$ $3.0 \times 10^{-5} \mathrm{~mm}^{2} /$ second) mice]. In addition, D2-mdx mice had significantly higher FA compared with B10- $m d x$ mice $(0.35 \pm 0.02$ versus $0.28 \pm 0.03 ; P<0.001)$. We did not find any difference in FA values of C57BL10 and B10- $m d x$ $(0.32 \pm 0.02$ versus $0.28 \pm 0.03)$. Finally, radial diffusion was significantly reduced in D2- $m d x$ compared with B10$m d x\left(1.1 \times 10^{-3} \pm 3.7 \times 10^{-5}\right.$ versus $1.2 \times 10^{-3} \pm$ $9.0 \times 10^{-5} \mathrm{~mm}^{2} /$ second) mice at 7 months of age.

\section{Decrease in Cardiac Function in D2-mdx Mice}

At 7 months of age, D2- $m d x$ mice demonstrated a significant decrease in cardiac function compared with B10- $m d x$ and DBA2 mice (Figure 6A). We did not find any significant differences in myocardial functional measurements of dystrophic mice groups [stroke volume (B10- $m d x$ versus $\mathrm{D} 2-m d x), 43.3 \pm 5.1 \mu \mathrm{L}$ versus $39.84 \pm 3.6 \mu \mathrm{L}$; \% ejection fraction $(\mathrm{B} 10-m d x$ versus $\mathrm{D} 2-m d x), 71.5 \% \pm 2.8 \%$ versus $64.9 \% \pm 4.4 \%$; and left ventricular mass (B10- $m d x$ versus $\mathrm{D} 2-m d x$ ), $63.4 \pm 5.1 \mathrm{mg}$ versus $64.4 \pm 2.8 \mathrm{mg}$ ] (Figure 6, $\mathrm{B}-\mathrm{G})$. However, these measurements were significantly different between D2- $m d x$ and DBA2 myocardium (stroke volume, $39.8 \pm 3.6 \mu \mathrm{L}$ versus $61.9 \pm 7.4 \mu \mathrm{L} ; \%$ ejection fraction, $64.9 \% \pm 4.4 \%$ versus $76.7 \% \pm 4.8 \%$; left ventricular mass, $64.4 \pm 2.8 \mathrm{mg}$ versus $84.5 \pm 5.2 \mathrm{mg}$ ). Furthermore, normalized end diastolic volume/body weight ratio in D2- $m d x$ mice was significantly higher compared with B10- $m d x$ mice. Finally, myocardial $\mathrm{T}_{2}$ of D2- $m d x$ mice compared with DBA2 mice was significantly decreased $(23.3 \pm 1.3$ milliseconds versus $27.2 \pm 1.4$ milliseconds; $P<0.01$ ) (Figure $6 \mathrm{H}$ ). We did not find any significant difference between B10- $m d x$ and D2- $m d x$ mice at this age.

\section{Histological Measurements}

Muscle cryosections from D2- $m d x$, DBA/2, and B10- $m d x$ mice were stained with $H \& E$ stains and quantified for fiber cross-sectional area, and the fibrotic tissue accumulation was quantified using Masson trichrome stain (Figure 7A). D2- $m d x$ mice demonstrated a significantly $(P<0.001)$ decreased fiber cross-sectional area compared with DBA2 and B10-mdx mice (Figure 7B). In comparison to DBA/2 and B10- $m d x$ muscles, D2- $m d x$ muscles exhibited significantly increased fibrosis (DBA2 versus D2- $m d x, 0.76 \%$ versus $18.24 \% ; P<0.001$ ) (Figure $7 \mathrm{C}$ ).

\section{Discussion}

In this study, we compared changes in MR parameters of skeletal and cardiac muscles in $m d x$ mice on two different genetic backgrounds (BL/10 and DBA/2J), known to exhibit vastly different levels of tissue fibrosis. ${ }^{20,59} \mathrm{We}$ observed the following: i) a decrease in $\mathrm{CSA}_{\max }$ of hindlimb muscles of D2- $m d x$ compared with B10- $m d x$, ii) an accelerated agedependent decrease in skeletal and cardiac muscle $\mathrm{T}_{2}$ in D2$m d x$ mice compared with $\mathrm{B} 10-m d x$, iii) differences in diffusion parameters in D2- $m d x$ mice compared with B10/ $m d x$ mice, in which these differences were related to differences in muscle fiber size, and iv) impaired cardiac functional measurements in D2- $m d x$ mice compared with age-matched B10- $m d x$ and DBA2 mice.

The $m d x$ mouse (C57BL/10-DMD $m d x$ ) model, on the C57BL/10ScSn background, has been the most widely used preclinical mouse model of DMD. Although dystrophin is absent in both DMD patients and the $m d x$ mouse model, the severity of disease varies considerably. In contrast to DMD, most hindlimb muscles of the $m d x$ mouse maintain skeletal muscle mass throughout much of their lifespan. Therefore, absence of dystrophin solely as the underlying cause of DMD fails to explain the variability in the disease progression. An increased body of evidence suggests that patients with DMD with the same mutation show marked differences in motor severity, implying the presence of genetic and environmental modifiers in muscular dystrophies that lead to considerable variability in disease progression. ${ }^{17,60}$ One source of this variation has been attributed to 
A

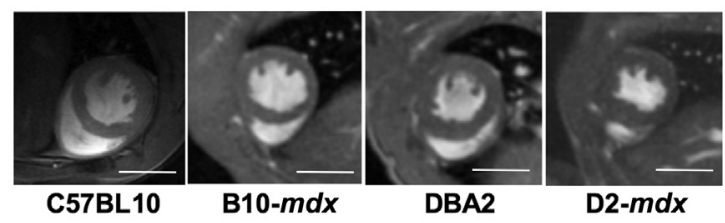

C

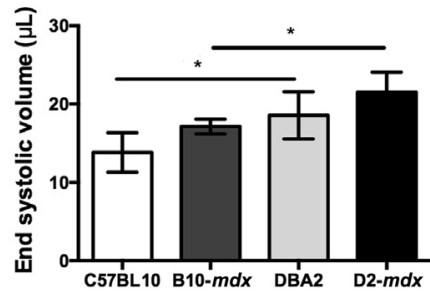

$F$

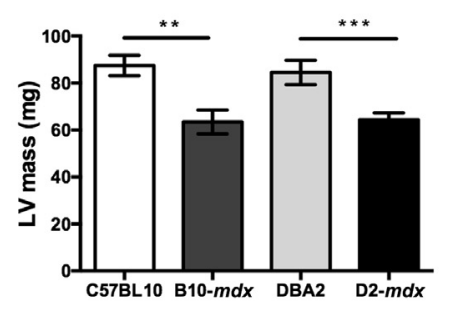

D

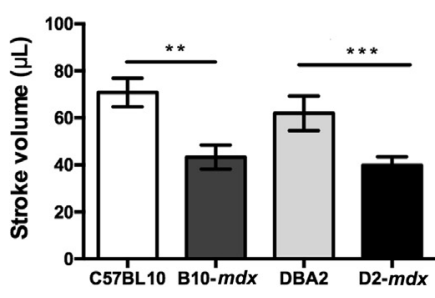

G

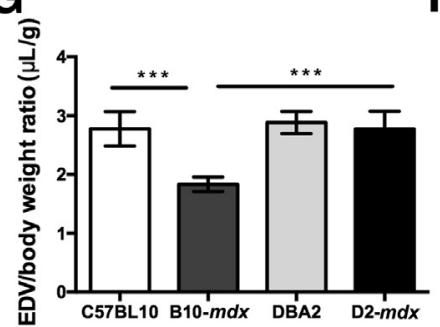

B

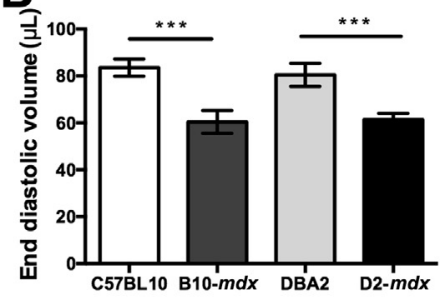

E

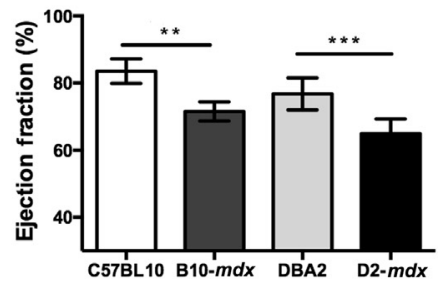

H

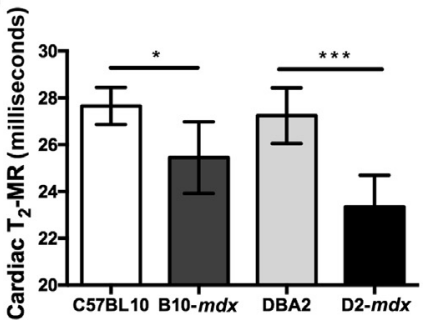

Figure 6 A: Representative two-chamber short axis cine slices at the level of papillary muscles at the end diastole in C57BL10, B10-mdx, DBA2, and D2$m d x$ mice. B-G: Cardiac functional data demonstrating significant differences between dystrophic mice on different background strain. H: Myocardium $\mathrm{T}_{2}$ reveals significant differences in DBA2 and D2- $m d x$ mice. Data are expressed as means $\pm \mathrm{SD}(\mathrm{B}-\mathrm{H}) .{ }^{*} P<0.05,{ }^{* *} P<0.01$, and ${ }^{* * *} P<0.001$. Scale bar $=10$ $\mathrm{mm}$ (A). EDV, end diastolic volume; LV, left ventricular.

the presence of the Ltbp4 gene encoding the latent transforming growth factor- $\beta$ binding protein 4 as a strong modifier of muscular dystrophy in both mice and humans. ${ }^{60,61}$

Studies have shown that specific mutations in the D2 strain make them more susceptible to age-related hearing loss, glaucoma, and calcified lesions of the testes, tongue, and skeletal muscles. ${ }^{62,63}$ In addition, there has been a growing body of evidence demonstrating an increase in pathology and fibrosis in dystrophic mice on the DBA/2J background compared with other backgrounds. ${ }^{19}$ Indeed, studies have reported a decrease in body weight and muscle weight in $m d x$ mice on the DBA/2J background. ${ }^{18,20}$ Moreover, Heydemann et $\mathrm{al}^{19}$ reported that $\gamma$-sarcoglycan null mice on the DBA/2 background showed decreased skeletal muscle weight, increased Evans Blue uptake, and higher hydroxyproline content than C57BL/6, CD1, and 129 backgrounds. Similarly, in this study, we have found that D2- $m d x$ mice were much smaller compared with control mice on the DBA background and B10-mdx mice. These data are consistent with the previously published studies showing that D2- $m d x$ mice depict an atrophic phenotype. ${ }^{20}$ MRI has been used to quantify muscle volume as well as $\mathrm{CSA}_{\max } \cdot{ }^{54,64}$ Using MRI as a noninvasive biomarker, we demonstrated that D2- $m d x$ mice had significantly reduced $\mathrm{CSA}_{\max }$ of both anterior and posterior compartment muscles compared with age-matched B10- $m d x$ and DBA/2J mice. MRI's noninvasive nature offers a unique opportunity to evaluate therapeutic measures aimed at increasing muscle mass, such as myostatin inhibitors or growth hormones in the same animal to address efficacy using the D2-mdx model.

The DBA/2J strain has been shown to be prone to extensive calcification in the presence of cardiac and skeletal muscle fibrosis. ${ }^{18}$ In the present study, we demonstrate that skeletal and cardiac muscles of D2- $m d x$ mice display lower $\mathrm{T}_{2}$ values compared with $\mathrm{B} 10-m d x$ mice. It has been well established that B10-mdx mice show increased fibrosis in the diaphragm by 6 months of age. ${ }^{65}$ Fibrotic tissue accumulation in hindlimb muscles increases significantly in old $m d x$ mice. ${ }^{59}$ MRI has been used to measure reduced signal intensity, which correlates with increase in fibrosis in heart ${ }^{66}$ and skeletal muscles. ${ }^{41}$ In this study, D2- $m d x$ mice displayed decreased skeletal and cardiac muscle $\mathrm{T}_{2}$ values earlier in life compared with B10- $m d x$ mice, and this decreased $T_{2}$ was associated with an increase in tissue fibrosis. In addition, a recent publication by Coley et $\mathrm{al}^{18}$ demonstrated that D2-mdx mice develop signs of cardiomyopathy much earlier than B10-mdx mice. Similar to the 
A
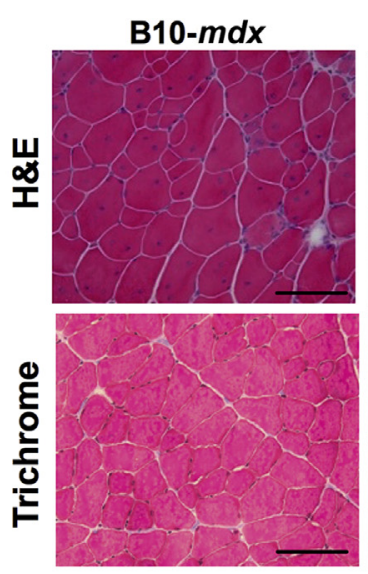

DBA2

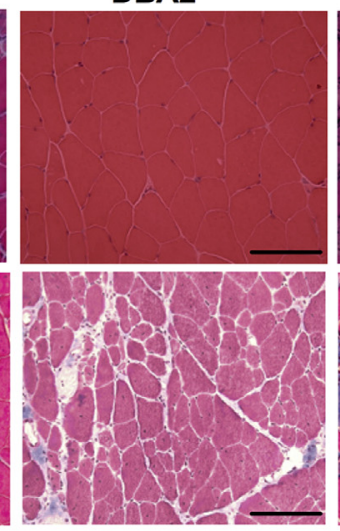

D2-mdx

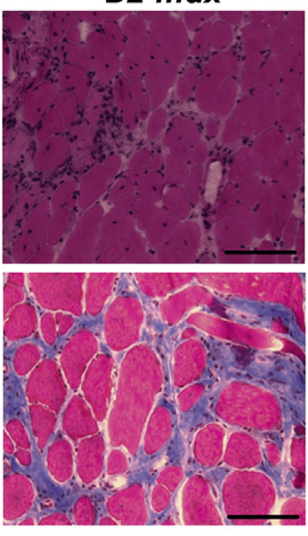

B
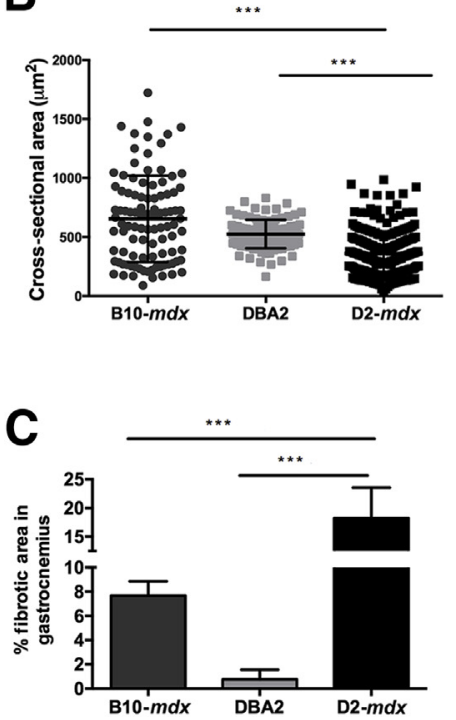

Figure 7 A: H\&E and trichrome stains of gastrocnemius muscle of B10- $m d x$, DBA2, and D2-mdx mice showing decrease in fiber size and increase in fibrotic tissue accumulation. B: D2-mdx mice have significantly reduced fiber cross-sectional areas compared with B10-mdx and DBA2 mice. C: Increased fibrotic tissue accumulation in gastrocnemius muscle of D2- $m d x$ mice compared with B10- $m d x$. Data are expressed as means \pm SD (B and C). *** $P<0.001$. Scale bar $=100$ $\mu \mathrm{m}(\mathbf{A})$. Original magnification, $\times 20(\mathbf{A})$.

previously published results, ${ }^{18}$ we also found a decrease in cardiac function and myocardial $\mathrm{T}_{2}$ of D2- $m d x$ mice at 7 months of age compared with B10-mdx and age-matched controls. In combination, both skeletal and cardiac muscles of D2-mdx mice exhibit accelerated age-dependent changes in fibrosis and function.

We further evaluated changes in water diffusivity in the presence of decreased muscle fiber size and fibrosis. Diffusion tensor image-based MR methods have been previously used to demonstrate variations in dystrophic muscle $^{67,68}$ and denervation models. ${ }^{64}$ It has been previously proposed that the change in eigenvalues and FA is indicative of change in muscle fiber morphology. ${ }^{69}$ Specifically, the principle eigenvalue $(\lambda 1)$ coincides with the long axis of the fibers, ${ }^{70,71} \lambda 2$ represents diffusion within the endomysium, and $\lambda 3$ represents diffusion within the cross section of a muscle fiber. ${ }^{72}$ Correspondingly, we found that diffusion parameters in D2- $m d x$ muscles were different compared with B10-mdx and control DBA2 mice. An increase in the degree of restricted diffusion of water may indicate change in the muscle architecture. ${ }^{69,73,74}$ Using the D2-mdx mouse model, we found that there was a decrease in both the mean diffusivity and radial diffusivity. Previously, using an injury model in $m d x$ mice, McMillan et al ${ }^{68}$ have demonstrated that with increase in edema there is increase in diffusion parameters, increase in muscle $\mathrm{T}_{2}$, and decrease in FA. Interestingly, in D2- $m d x$ muscles, at 7 months of age, we found that $T_{2}$ and diffusion parameters decreased, whereas there was an increase in FA. Histologically, we observed an increase in fibrous/collagenous tissue deposition and a decrease in muscle fiber size, suggesting a fibrotic and atrophic phenotype in D2-mdx mice. Our histological results are in agreement with previously published results, where they demonstrated that D2- $m d x$ mice displayed a decrease in mean fiber CSA, which can significantly affect skeletal muscle diffusion tensor image-MR measurements in mice at long diffusion times. ${ }^{18}$ In addition, we observed accumulation in fibrotic/ collagenous material around the muscle fibers, which could contribute to a decrease in $\lambda 2$. Previous studies have also reported an increase in fibrotic material in dystrophic mice on the DBA/2J background. ${ }^{61}$ Finally, we have demonstrated a decrease in $\lambda 3$ eigenvalue, which is hypothesized to correspond to muscle fiber size. ${ }^{75}$ In support of the MR results, we correlated the MRI findings with histological measures and found that there is a decrease in muscle fiber size but also an increase in fibrotic tissue accumulation. These results are somewhat surprising because the diffusion times used in this study are relatively short, precluding the measurement of fiber diameter, possibly indicating that increased intracellular diffusive barriers exist in the D2-mdx muscles. Future studies using variable b values and diffusion times or magnetic resonance spectroscopybased diffusion measurements could help provide insight. ${ }^{76}$ Results of previous studies have also shown a decrease in muscle fiber size of D2- $m d x$ muscles compared with B10- $m d x$ muscles. ${ }^{18,20}$

An increased body of evidence suggests a decrease in cardiac function with age in dystrophic mice. ${ }^{18,77}$ Similarly, our evaluations revealed significant differences in stroke volume and ejection fraction between dystrophic mice (ie, B10-mdx and D2-mdx and their age- and strain-matched control mice). However, we did not find significant differences between B10- $m d x$ and D2- $m d x$ mice at 7 months of 
age. One of the reasons is that the cardiac muscles in B10$m d x$ mice are also affected between ages of 6 and 9 months. Furthermore, a study by Ballmann et $\mathrm{al}^{38}$ demonstrated that cardiac magnetic resonance $T_{2}$ can detect beneficial effects of long-term dietary quercetin enrichment. In addition, fibrotic tissue accumulation has been demonstrated in dystrophic myocardium. ${ }^{77}$ Fibrotic tissue accumulation is an important feature in muscular dystrophy. Finally, we found a decrease in myocardium $T_{2}$ in both dystrophic strains at 7 months of age. Further exploration of the genetic and physiological differences between the two dystrophic strains is warranted.

It is important to consider the limitations of this study. First, there are a multitude of underlying factors that coexist in dystrophic muscles. For example, change in muscle permeability, loss of external or internal fibers, and/or reduction in fiber diameter are some factors, and these changes can be measured using range of diffusion time, ranging from 80 to 200 milliseconds. ${ }^{76}$ Another limitation of the study is the use of different $b$ values compared with previously published values. Previously published studies have used a b value of 400 to $500 \mathrm{sec}$ onds $/ \mathrm{mm}^{2},{ }^{64,73,75}$ whereas in the present study, we have used $a b$ value of 900 seconds $/ \mathrm{mm}^{2}$. The signal/noise ratio of images with a minimum b value was 29.11 , which is close to the previously published studies. ${ }^{64}$ However, in this study, we were unable to use the advanced diffusion techniques to measure cell structure and dimensions, which should be incorporated in the future studies to corroborate MR results. Another limitation of this study is the absolute quantification of fibrotic tissue accumulation in myocardium in dystrophic mice using MRI. However, studies in the past have demonstrated that myocardium $T_{2}$ can be used as a surrogate measure to monitor fibrotic tissue accumulation. ${ }^{45}$ Despite all of the limitations, we hope our study forms a platform for future studies using advanced MR methods to demonstrate the inherent differences between dystrophic mice on different backgrounds.

In summary, we demonstrate that $m d x$ mice on the DBA background show increased skeletal muscle and cardiac pathology compared with the BL/10 background. Furthermore, MRI of skeletal and cardiac muscle was found to be able to differentiate between these models and may prove to be a sensitive surrogate measure for detecting the underlying pathophysiological changes in mouse models of dystrophy. In addition to MRI being a noninvasive measure, it can be serially applied to the same animal, as in this study, and may help to reduce cost and achieve the wanted statistical power for preclinical therapeutic screening with fewer animals.

\section{Supplemental Data}

Supplemental material for this article can be found at http://dx.doi.org/10.1016/j.ajpath.2017.05.010.

\section{References}

1. Bonnemann CG, McNally EM, Kunkel LM: Beyond dystrophin: current progress in the muscular dystrophies. Curr Opin Pediatr 1996, 8:569-582

2. Allamand V, Campbell KP: Animal models for muscular dystrophy: valuable tools for the development of therapies. Hum Mol Genet 2000, 9:2459-2467

3. Pastoret C, Sebille A: mdx Mice show progressive weakness and muscle deterioration with age. J Neurol Sci 1995, 129:97-105

4. Bell CD, Conen PE: Histopathological changes in Duchenne muscular dystrophy. J Neurol Sci 1968, 7:529-544

5. Pons F, Robert A, Fabbrizio E, Hugon G, Califano JC, Fehrentz JA, Martinez J, Mornet D: Utrophin localization in normal and dystrophin-deficient heart. Circulation 1994, 90:369-374

6. Banks GB, Chamberlain JS: The value of mammalian models for duchenne muscular dystrophy in developing therapeutic strategies. Curr Top Dev Biol 2008, 84:431-453

7. Gregorevic P, Blankinship MJ, Allen JM, Crawford RW, Meuse L, Miller DG, Russell DW, Chamberlain JS: Systemic delivery of genes to striated muscles using adeno-associated viral vectors. Nat Med 2004, 10:828-834

8. Cox GA, Cole NM, Matsumura K, Phelps SF, Hauschka SD, Campbell KP, Faulkner JA, Chamberlain JS: Overexpression of dystrophin in transgenic mdx mice eliminates dystrophic symptoms without toxicity. Nature 1993, 364:725-729

9. Welch EM, Barton ER, Zhuo J, Tomizawa Y, Friesen WJ, Trifillis P, et al: PTC124 targets genetic disorders caused by nonsense mutations. Nature 2007, 447:87-91

10. Barton-Davis ER, Cordier L, Shoturma DI, Leland SE, Sweeney HL: Aminoglycoside antibiotics restore dystrophin function to skeleta muscles of mdx mice. J Clin Invest 1999, 104:375-381

11. Muntoni F, Wells D: Genetic treatments in muscular dystrophies Curr Opin Neurol 2007, 20:590-594

12. Wood MJ, Gait MJ, Yin H: RNA-targeted splice-correction therapy for neuromuscular disease. Brain 2010, 133:957-972

13. Gussoni E, Soneoka Y, Strickland CD, Buzney EA, Khan MK, Flint AF, Kunkel LM, Mulligan RC: Dystrophin expression in the mdx mouse restored by stem cell transplantation. Nature 1999, 401: 390-394

14. Beggs AH, Hoffman EP, Snyder JR, Arahata K, Specht L, Shapiro F, Angelini C, Sugita H, Kunkel LM: Exploring the molecular basis for variability among patients with Becker muscular dystrophy: dystrophin gene and protein studies. Am J Hum Genet 1991, 49:54-67

15. Muntoni F, Gobbi P, Sewry C, Sherratt T, Taylor J, Sandhu SK, Abbs S, Roberts R, Hodgson SV, Bobrow M: Deletions in the 5' region of dystrophin and resulting phenotypes. J Med Genet 1994, 31 : 843-847

16. Sifringer M, Uhlenberg B, Lammel S, Hanke R, Neumann B, von Moers A, Koch I, Speer A: Identification of transcripts from a subtraction library which might be responsible for the mild phenotype in an intrafamilially variable course of Duchenne muscular dystrophy. Hum Genet 2004, 114:149-156

17. McNally EM, Passos-Bueno MR, Bonnemann CG, Vainzof M, de Sa Moreira E, Lidov HG, Othmane KB, Denton PH, Vance JM, Zatz M, Kunkel LM: Mild and severe muscular dystrophy caused by a single gamma-sarcoglycan mutation. Am J Hum Genet 1996, 59: 1040-1047

18. Coley WD, Bogdanik L, Vila MC, Yu Q, Van Der Meulen JH, Rayavarapu S, Novak JS, Nearing M, Quinn JL, Saunders A, Dolan C, Andrews W, Lammert C, Austin A, Partridge TA, Cox GA, Lutz C, Nagaraju K: Effect of genetic background on the dystrophic phenotype in $\mathrm{mdx}$ mice. Hum Mol Genet 2016, 25:130-145

19. Heydemann A, Huber JM, Demonbreun A, Hadhazy M, McNally EM: Genetic background influences muscular dystrophy. Neuromuscul Disord 2005, 15:601-609 
20. Fukada S, Morikawa D, Yamamoto Y, Yoshida T, Sumie N, Yamaguchi M, Ito T, Miyagoe-Suzuki Y, Takeda S, Tsujikawa K, Yamamoto $\mathrm{H}$ : Genetic background affects properties of satellite cells and mdx phenotypes. Am J Pathol 2010, 176:2414-2424

21. Gelman R, Watson A, Bronson R, Yunis E: Murine chromosomal regions correlated with longevity. Genetics 1988, 118:693-704

22. Gutpell KM, Hrinivich WT, Hoffman LM: Skeletal muscle fibrosis in the mdx/utrn $+/$ - mouse validates its suitability as a murine model of Duchenne muscular dystrophy. PLoS One 2015, 10:e0117306

23. Arpan I, Forbes SC, Lott DJ, Senesac CR, Daniels MJ, Triplett WT, Deol JK, Sweeney HL, Walter GA, Vandenborne K: T(2) mapping provides multiple approaches for the characterization of muscle involvement in neuromuscular diseases: a cross-sectional study of lower leg muscles in 5-15-year-old boys with Duchenne muscular dystrophy. NMR Biomed 2013, 26:320-328

24. Pillen S, Tak RO, Zwarts MJ, Lammens MM, Verrijp KN, Arts IM, van der Laak JA, Hoogerbrugge PM, van Engelen BG, Verrips A: Skeletal muscle ultrasound: correlation between fibrous tissue and echo intensity. Ultrasound Med Biol 2009, 35:443-446

25. Arts IM, Schelhaas HJ, Verrijp KC, Zwarts MJ, Overeem S, van der Laak JA, Lammens MM, Pillen S: Intramuscular fibrous tissue determines muscle echo intensity in amyotrophic lateral sclerosis. Muscle Nerve 2012, 45:449-450

26. Zaidman CM, Wang LL, Connolly AM, Florence J, Wong BL, Parsons JA, Apkon S, Goyal N, Williams E, Escolar D, Rutkove SB, Bohorquez JL; DART-EIM Clinical Evaluators Consortium: Electrical impedance myography in Duchenne muscular dystrophy and healthy controls: a multicenter study of reliability and validity. Muscle Nerve 2015, 52:592-597

27. Sanchez B, Li J, Yim S, Pacheck A, Widrick JJ, Rutkove SB: Evaluation of electrical impedance as a biomarker of myostatin inhibition in wild type and muscular dystrophy mice. PLoS One 2015, 10:e0140521

28. Schreiber A, Smith WL, Ionasescu V, Zellweger H, Franken EA, Dunn V, Ehrhardt J: Magnetic resonance imaging of children with Duchenne muscular dystrophy. Pediatr Radiol 1987, 17:495-497

29. Liu GC, Jong YJ, Chiang CH, Jaw TS: Duchenne muscular dystrophy: MR grading system with functional correlation. Radiology 1993 , 186:475-480

30. Barbiroli B, McCully KK, Iotti S, Lodi R, Zaniol P, Chance B: Further impairment of muscle phosphate kinetics by lengthening exercise in DMD/BMD carriers: an in vivo 31P-NMR spectroscopy study. J Neurol Sci 1993, 119:65-73

31. Huang Y, Majumdar S, Genant HK, Chan WP, Sharma KR, Yu P, Mynhier M, Miller RG: Quantitative MR relaxometry study of muscle composition and function in Duchenne muscular dystrophy. J Magn Reson Imaging 1994, 4:59-64

32. Mathur S, Lott DJ, Senesac C, Germain SA, Vohra RS, Sweeney HL, Walter GA, Vandenborne K: Age-related differences in lower-limb muscle cross-sectional area and torque production in boys with Duchenne muscular dystrophy. Arch Phys Med Rehabil 2010, 91:1051-1058

33. Kinali M, Arechavala-Gomeza V, Cirak S, Glover A, Guglieri M, Feng L, Hollingsworth KG, Hunt D, Jungbluth H, Roper HP, Quinlivan RM, Gosalakkal JA, Jayawant S, Nadeau A, HughesCarre L, Manzur AY, Mercuri E, Morgan JE, Straub V, Bushby K, Sewry C, Rutherford M, Muntoni F: Muscle histology vs MRI in Duchenne muscular dystrophy. Neurology 2011, 76:346-353

34. Arpan I, Willcocks RJ, Forbes SC, Finkel RS, Lott DJ, Rooney WD, Triplett WT, Senesac CR, Daniels MJ, Byrne BJ, Finanger EL, Russman BS, Wang DJ, Tennekoon GI, Walter GA, Sweeney HL, Vandenborne K: Examination of effects of corticosteroids on skeletal muscles of boys with DMD using MRI and MRS. Neurology 2014, 83:974-980

35. Mathur S, Vohra RS, Germain SA, Forbes S, Bryant ND, Vandenborne K, Walter GA: Changes in muscle T2 and tissue damage after downhill running in mdx mice. Muscle Nerve 2011, 43 : 878-886
36. Bryant ND, Li K, Does MD, Barnes S, Gochberg DF, Yankeelov TE, Park JH, Damon BM: Multi-parametric MRI characterization of inflammation in murine skeletal muscle. NMR Biomed 2014, 27: $716-725$

37. Fan RH, Does MD: Compartmental relaxation and diffusion tensor imaging measurements in vivo in lambda-carrageenan-induced edema in rat skeletal muscle. NMR Biomed 2008, 21:566-573

38. Ballmann C, Denney TS, Beyers RJ, Quindry T, Romero M, Amin R, Selsby JT, Quindry JC: Lifelong quercetin enrichment and cardioprotection in Mdx/Utrn+/- mice. Am J Physiol Heart Circ Physiol 2017, 312:H128-H140

39. Elder CP, Apple DF, Bickel CS, Meyer RA, Dudley GA: Intramuscular fat and glucose tolerance after spinal cord injury: a crosssectional study. Spinal Cord 2004, 42:711-716

40. Bo Li Z, Zhang J, Wagner KR: Inhibition of myostatin reverses muscle fibrosis through apoptosis. J Cell Sci 2012, 125:3957-3965

41. Vohra R, Accorsi A, Kumar A, Walter G, Girgenrath M: Magnetic resonance imaging is sensitive to pathological amelioration in a model for laminin-deficient congenital muscular dystrophy (MDC1A). PLoS One 2015, 10:e0138254

42. Puchalski MD, Williams RV, Askovich B, Sower CT, Hor KH, Su JT, Pack N, Dibella E, Gottliebson WM: Late gadolinium enhancement: precursor to cardiomyopathy in Duchenne muscular dystrophy? Int J Cardiovasc Imaging 2009, 25:57-63

43. Hor KN, Taylor MD, Al-Khalidi HR, Cripe LH, Raman SV, Jefferies JL, O'Donnell R, Benson DW, Mazur W: Prevalence and distribution of late gadolinium enhancement in a large population of patients with Duchenne muscular dystrophy: effect of age and left ventricular systolic function. J Cardiovasc Magn Reson 2013, 15:107

44. Florian A, Ludwig A, Engelen M, Waltenberger J, Rosch S, Sechtem U, Yilmaz A: Left ventricular systolic function and the pattern of late-gadolinium-enhancement independently and additively predict adverse cardiac events in muscular dystrophy patients. J Cardiovasc Magn Reson 2014, 16:81

45. van Nierop BJ, Bax NA, Nelissen JL, Arslan F, Motaal AG, de Graaf L, Zwanenburg JJ, Luijten PR, Nicolay K, Strijkers GJ: Assessment of myocardial fibrosis in mice using a T2*-weighted 3D radial magnetic resonance imaging sequence. PLoS One 2015, 10: e0129899

46. Egger C, Gerard C, Vidotto N, Accart N, Cannet C, Dunbar A, Tigani B, Piaia A, Jarai G, Jarman E, Schmid HA, Beckmann N: Lung volume quantified by MRI reflects extracellular-matrix deposition and altered pulmonary function in bleomycin models of fibrosis: effects of SOM230. Am J Physiol Lung Cell Mol Physiol 2014, 306:L1064-L1077

47. Quinlan JG, Hahn HS, Wong BL, Lorenz JN, Wenisch AS, Levin LS: Evolution of the mdx mouse cardiomyopathy: physiological and morphological findings. Neuromuscul Disord 2004, 14:491-496

48. Martins-Bach AB, Malheiros J, Matot B, Martins PC, Almeida CF, Caldeira W, Ribeiro AF, Loureiro de Sousa P, Azzabou N, Tannus A, Carlier PG, Vainzof M: Quantitative T2 combined with texture analysis of nuclear magnetic resonance images identify different degrees of muscle involvement in three mouse models of muscle dystrophy: mdx, Largemyd and mdx/Largemyd. PLoS One 2015, 10: e0117835

49. Hsu EW, Schoeniger JS, Bowtell R, Aiken NR, Horsman A, Blackband SJ: A modified imaging sequence for accurate T2 measurements using NMR microscopy. J Magn Reson B 1995, 109: 66-69

50. Triplett WT, Baligand C, Forbes SC, Willcocks RJ, Lott DJ, DeVos S, Pollaro J, Rooney WD, Sweeney HL, Bonnemann CG, Wang DJ, Vandenborne K, Walter GA: Chemical shift-based MRI to measure fat fractions in dystrophic skeletal muscle. Magn Reson Med 2014, 72:8-19

51. Araujo EC, Fromes Y, Carlier PG: New insights on human skeletal muscle tissue compartments revealed by in vivo t2 NMR relaxometry. Biophys J 2014, 106:2267-2274 
52. Saab G, Thompson RT, Marsh GD: Effects of exercise on muscle transverse relaxation determined by MR imaging and in vivo relaxometry. J Appl Physiol (1985) 2000, 88:226-233

53. Graham SJ, Stanchev PL, Bronskill MJ: Criteria for analysis of multicomponent tissue T2 relaxation data. Magn Reson Med 1996, 35:370-378

54. Ye F, Baligand C, Keener JE, Vohra R, Lim W, Ruhella A, Bose P, Daniels M, Walter GA, Thompson F, Vandenborne K: Hindlimb muscle morphology and function in a new atrophy model combining spinal cord injury and cast immobilization. J Neurotrauma 2013, 30: 227-235

55. Forbes SC, Willcocks RJ, Triplett WT, Rooney WD, Lott DJ, Wang DJ, Pollaro J, Senesac CR, Daniels MJ, Finkel RS, Russman BS, Byrne BJ, Finanger EL, Tennekoon GI, Walter GA, Sweeney HL, Vandenborne K: Magnetic resonance imaging and spectroscopy assessment of lower extremity skeletal muscles in boys with Duchenne muscular dystrophy: a multicenter cross sectional study. PLoS One 2014, 9:e106435

56. Majumdar S, Kotecha M, Triplett W, Epel B, Halpern H: A DTI study to probe tumor microstructure and its connection with hypoxia. Conf Proc IEEE Eng Med Biol Soc 2014, 2014:738-741

57. Manning WJ, Wei JY, Katz SE, Litwin SE, Douglas PS: In vivo assessment of LV mass in mice using high-frequency cardiac ultrasound: necropsy validation. Am J Physiol 1994, 266:H1672-H1675

58. Stuckey DJ, Carr CA, Tyler DJ, Aasum E, Clarke K: Novel MRI method to detect altered left ventricular ejection and filling patterns in rodent models of disease. Magn Reson Med 2008, 60:582-587

59. Lefaucheur JP, Pastoret C, Sebille A: Phenotype of dystrophinopathy in old mdx mice. Anat Rec 1995, 242:70-76

60. Flanigan KM, Ceco E, Lamar KM, Kaminoh Y, Dunn DM, Mendell JR, King WM, Pestronk A, Florence JM, Mathews KD, Finkel RS, Swoboda KJ, Gappmaier E, Howard MT, Day JW, McDonald C, McNally EM, Weiss RB; United Dystrophinopathy Project: LTBP4 genotype predicts age of ambulatory loss in Duchenne muscular dystrophy. Ann Neurol 2013, 73:481-488

61. Heydemann A, Ceco E, Lim JE, Hadhazy M, Ryder P, Moran JL, Beier DR, Palmer AA, McNally EM: Latent TGF-beta-binding protein 4 modifies muscular dystrophy in mice. J Clin Invest 2009, 119: 3703-3712

62. Neumann PE, Collins RL: Genetic dissection of susceptibility to audiogenic seizures in inbred mice. Proc Natl Acad Sci U S A 1991, 88:5408-5412

63. Libby RT, Anderson MG, Pang IH, Robinson ZH, Savinova OV, Cosma IM, Snow A, Wilson LA, Smith RS, Clark AF, John SW: Inherited glaucoma in DBA/2J mice: pertinent disease features for studying the neurodegeneration. Vis Neurosci 2005, 22:637-648
64. Zhang J, Zhang G, Morrison B, Mori S, Sheikh KA: Magnetic resonance imaging of mouse skeletal muscle to measure denervation atrophy. Exp Neurol 2008, 212:448-457

65. Stedman HH, Sweeney HL, Shrager JB, Maguire HC, Panettieri RA, Petrof B, Narusawa M, Leferovich JM, Sladky JT, Kelly AM: The $\mathrm{mdx}$ mouse diaphragm reproduces the degenerative changes of Duchenne muscular dystrophy. Nature 1991, 352:536-539

66. de Jong S, Zwanenburg JJ, Visser F, der Nagel R, van Rijen HV, Vos MA, de Bakker JM, Luijten PR: Direct detection of myocardial fibrosis by MRI. J Mol Cell Cardiol 2011, 51:974-979

67. Park J, Wicki J, Knoblaugh SE, Chamberlain JS, Lee D: Multiparametric MRI at $14 \mathrm{~T}$ for muscular dystrophy mice treated with AAV vector-mediated gene therapy. PLoS One 2015, 10:e0124914

68. McMillan AB, Shi D, Pratt SJ, Lovering RM: Diffusion tensor MRI to assess damage in healthy and dystrophic skeletal muscle after lengthening contractions. J Biomed Biotechnol 2011, 2011:970726

69. Heemskerk AM, Strijkers GJ, Vilanova A, Drost MR, Nicolay K: Determination of mouse skeletal muscle architecture using three-dimensional diffusion tensor imaging. Magn Reson Med 2005, $53: 1333-1340$

70. Van Donkelaar CC, Kretzers LJ, Bovendeerd PH, Lataster LM, Nicolay K, Janssen JD, Drost MR: Diffusion tensor imaging in biomechanical studies of skeletal muscle function. J Anat 1999, 194(Pt 1):79-88

71. van Doorn A, Bovendeerd PH, Nicolay K, Drost MR, Janssen JD Determination of muscle fibre orientation using diffusion-weighted MRI. Eur J Morphol 1996, 34:5-10

72. Tseng WY, Wedeen VJ, Reese TG, Smith RN, Halpern EF: Diffusion tensor MRI of myocardial fibers and sheets: correspondence with visible cut-face texture. J Magn Reson Imaging 2003, 17:31-42

73. Damon BM, Ding Z, Anderson AW, Freyer AS, Gore JC: Validation of diffusion tensor MRI-based muscle fiber tracking. Magn Reson Med 2002, 48:97-104

74. Cleveland GG, Chang DC, Hazlewood CF, Rorschach HE: Nuclear magnetic resonance measurement of skeletal muscle: anisotrophy of the diffusion coefficient of the intracellular water. Biophys J 1976, 16:1043-1053

75. Galban CJ, Maderwald S, Uffmann K, de Greiff A, Ladd ME: Diffusive sensitivity to muscle architecture: a magnetic resonance diffusion tensor imaging study of the human calf. Eur J Appl Physiol 2004, 93:253-262

76. Hall MG, Clark CA: Diffusion in hierarchical systems: a simulation study in models of healthy and diseased muscle tissue. Magn Reson Med 2016, [Epub ahead of print] doi:10.1002/mrm.26469

77. Li W, Liu W, Zhong J, Yu X: Early manifestation of alteration in cardiac function in dystrophin deficient mdx mouse using 3D CMR tagging. J Cardiovasc Magn Reson 2009, 11:40 